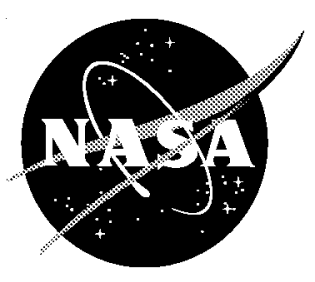

\title{
Development of a Flush Airdata Sensing System on a Sharp-Nosed Vehicle for Flight at Mach 3 to 8
}

Mark C. Davis, Joseph W. Pahle, John Terry White, and Laurie A. Marshall NASA Dryden Flight Research Center Edwards, California

Michael J. Mashburn

Micro Craft, Inc.

Tullahoma, Tennessee

Rick Franks

Sverdrup Corp.

Arnold Air Force Base, Tennessee 


\section{The NASA STI Program Office...in Profile}

Since its founding, NASA has been dedicated to the advancement of aeronautics and space science. The NASA Scientific and Technical Information (STI) Program Office plays a key part in helping NASA maintain this important role.

The NASA STI Program Office is operated by Langley Research Center, the lead center for NASA's scientific and technical information. The NASA STI Program Office provides access to the NASA STI Database, the largest collection of aeronautical and space science STI in the world. The Program Office is also NASA's institutional mechanism for disseminating the results of its research and development activities. These results are published by NASA in the NASA STI Report Series, which includes the following report types:

- TECHNICAL PUBLICATION. Reports of completed research or a major significant phase of research that present the results of NASA programs and include extensive data or theoretical analysis. Includes compilations of significant scientific and technical data and information deemed to be of continuing reference value. NASA's counterpart of peer-reviewed formal professional papers but has less stringent limitations on manuscript length and extent of graphic presentations.

- TECHNICAL MEMORANDUM. Scientific and technical findings that are preliminary or of specialized interest, e.g., quick release reports, working papers, and bibliographies that contain minimal annotation. Does not contain extensive analysis.

- CONTRACTOR REPORT. Scientific and technical findings by NASA-sponsored contractors and grantees.
- CONFERENCE PUBLICATION.

Collected papers from scientific and technical conferences, symposia, seminars, or other meetings sponsored or cosponsored by NASA.

- SPECIAL PUBLICATION. Scientific, technical, or historical information from NASA programs, projects, and mission, often concerned with subjects having substantial public interest.

- TECHNICAL TRANSLATION. Englishlanguage translations of foreign scientific and technical material pertinent to NASA's mission.

Specialized services that complement the STI Program Office's diverse offerings include creating custom thesauri, building customized databases, organizing and publishing research results...even providing videos.

For more information about the NASA STI Program Office, see the following:

- Access the NASA STI Program Home Page at http://www.sti.nasa.gov

- E-mail your question via the Internet to help@sti.nasa.gov

- Fax your question to the NASA Access Help Desk at (301) 621-0134

- Telephone the NASA Access Help Desk at (301) 621-0390

- Write to: NASA Access Help Desk NASA Center for AeroSpace Information 7121 Standard Drive Hanover, MD 21076-1320 


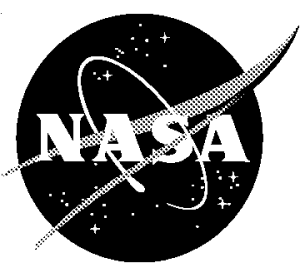

\section{Development of a Flush Airdata Sensing System on a Sharp-Nosed Vehicle for Flight at Mach 3 to 8}

Mark C. Davis, Joseph W. Pahle, John Terry White, and Laurie A. Marshall NASA Dryden Flight Research Center Edwards, California

Michael J. Mashburn

Micro Craft, Inc.

Tullahoma, Tennessee

Rick Franks

Sverdrup Corp.

Arnold Air Force Base, Tennessee

National Aeronautics and

Space Administration

Dryden Flight Research Center

Edwards, California 93523-0273 


\section{NOTICE}

Use of trade names or names of manufacturers in this document does not constitute an official endorsement of such products or manufacturers, either expressed or implied, by the National Aeronautics and Space Administration.

Available from the following:

NASA Center for AeroSpace Information (CASI)

7121 Standard Drive

Hanover, MD 21076-1320

(301) 621-0390
National Technical Information Service (NTIS) 5285 Port Royal Road Springfield, VA 22161-2171 (703) $487-4650$ 


\begin{abstract}
NASA Dryden Flight Research Center has developed a flush airdata sensing (FADS) system on a sharp-nosed, wedge-shaped vehicle. This paper details the design and calibration of a real-time angle-ofattack estimation scheme developed to meet the onboard airdata measurement requirements for a research vehicle equipped with a supersonic-combustion ramjet engine. The FADS system has been designed to perform in flights at speeds between Mach 3 and Mach 8 and at angles of attack between $-6^{\circ}$ and $12^{\circ}$. The description of the FADS architecture includes port layout, pneumatic design, and hardware integration. Predictive models of static and dynamic performance are compared with wind-tunnel results across the Mach and angle-of-attack range. Results indicate that static angle-of-attack accuracy and pneumatic lag can be adequately characterized and incorporated into a real-time algorithm.
\end{abstract}

\title{
NOMENCLATURE
}

\section{Acronyms}

$\begin{array}{ll}\text { FADS } & \text { flush airdata sensing } \\ \text { INS } & \text { inertial navigation system } \\ \text { L } & \text { pneumatic line designation } \\ \text { PPT } & \text { precision pressure transducer } \\ \text { SCRamjet } & \text { supersonic-combustion ramjet }\end{array}$

\section{Symbols}

$\mathrm{C}_{\mathrm{PPT}} \quad$ transducer calibration as a function of Mach number

$D \quad$ diameter of lines from port to transducer, in.

$F A D S_{\alpha_{1}} \quad$ forward angle-of-attack estimate, deg

$F A D S_{\alpha_{2}} \quad$ rear angle-of-attack estimate, deg

$F A D S_{\alpha_{3}} \quad$ pseudodifferential angle-of-attack estimate, deg

$g \quad$ acceleration caused by gravity, $\mathrm{ft} / \mathrm{sec}^{2}$

i arbitrary integer

$k \quad$ lag constant

$L \quad$ pneumatic line length, $\mathrm{ft}$

$P_{P P T} \quad$ measured pressure at transducer, $1 \mathrm{bf} / \mathrm{ft}^{2}$

$P_{\text {port }} \quad$ measured pressure at port, $1 \mathrm{bf} / \mathrm{ft}^{2}$

$\bar{q} \quad$ dynamic pressure, $\mathrm{lbf} / \mathrm{ft}^{2}$

$\mathrm{q}_{1} \quad$ weighting function

$s \quad$ Laplace frequency variable 


$\begin{array}{ll}V_{e} & \text { effective volume of the measurement system, } \mathrm{ft}^{3} \\ \mathrm{X} / \mathrm{L} & \text { body axis location } \\ \alpha & \text { angle of attack, deg } \\ \alpha_{\text {est }} & \text { bias angle of attack, deg } \\ \alpha_{\text {FADS }} & \text { reference angle of attack derived from the FADS algorithm, deg } \\ \alpha_{I N S} & \text { angle of attack derived from the inertial navigation system, deg } \\ \alpha_{\text {true }} & \text { angle of attack obtained from wind tunnel, deg } \\ \beta & \text { angle of sideslip, deg } \\ \Delta & \text { difference } \\ \mu & \text { dynamic viscosity of the air in the line, lbm/(ft/sec) } \\ \tau & \text { time constant }\end{array}$

\section{INTRODUCTION}

The National Aeronautics and Space Administration and aerospace community are developing airbreathing propulsion systems capable of flight at hypersonic speeds. One promising concept is the supersonic-combustion ramjet (SCRamjet) engine (ref. 1). The current design of SCRamjets allows supersonic combustion to occur only in a narrow operating range.

Dynamic pressure $(\bar{q})$ and angle of attack $(\alpha)$ are two of the critical parameters that determine the flow into the engine inlet. Accurate measurement of these parameters is desired for real-time control and is required for postflight analysis. Accurately estimating angle of attack from the inertial navigation system (INS) alone is difficult because of atmospheric variations and sensor installation and performance (ref. 2). This requirement led to the development of a nonintrusive system, the flush airdata sensing (FADS) system, that has the ability to measure angle of attack in real time and allow the remainder of the airdata parameters to be reconstructed postflight.

The FADS concept uses a matrix of flush surface ports to infer airdata. The FADS system has been successfully applied to a variety of blunt forebodies (refs. 3-7), and one feasibility study (ref. 1) has been conducted for a sharp-nosed, hypersonic configuration. To be a viable system, the FADS system must measure angle of attack to within $0.5^{\circ}$ (because of the criticality of incidence angle of the engine inlet); measure dynamic pressure to within 5 percent for postflight analysis; and survive the intense thermal environment in which a hypersonic vehicle flies (ref. 8). This paper presents the architecture, estimation algorithms, and wind-tunnel calibration of a FADS system intended for a sharp-nosed, SCRamjet test vehicle.

\section{FLUSH AIRDATA SENSING SYSTEM ARCHITECTURE OVERVIEW}

This section describes the pneumatic architecture of the FADS system. The port layout, the sensing transducer characteristics, and the pneumatic layout of the pressure sensing system are described. The sensing components that comprise the real-time airdata system are distinguished from those used for the postflight algorithm. 


\section{Pressure Port Layout}

A matrix of nine pressure ports is used to sense the airdata parameters. Figure 1 shows the locations of these ports on the vehicle forebody. Four ports (indicated by the highlighted symbols along the centerline of the forebody in figure 1) are used to indirectly sense the angle of attack. The remaining five pressure ports (indicated by the open symbols in figure 1) are used for postflight evaluation of the remaining airdata parameters. To save real-time bandwidth and ensure a high data throughput, the system architecture decouples the angle-of-attack estimation from the remainder of the postflight algorithm. Only the pressure data from the angle-of-attack ports is used in real time and combined with the inertial angle of attack to estimate a high-fidelity, vehicle angle of attack.

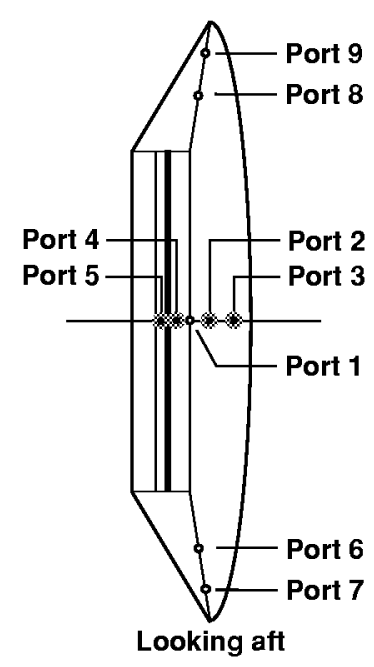

( ) Indicates port is located on test article upper fuselage

[ ] Indicates port is located on test article right side of the fuselage
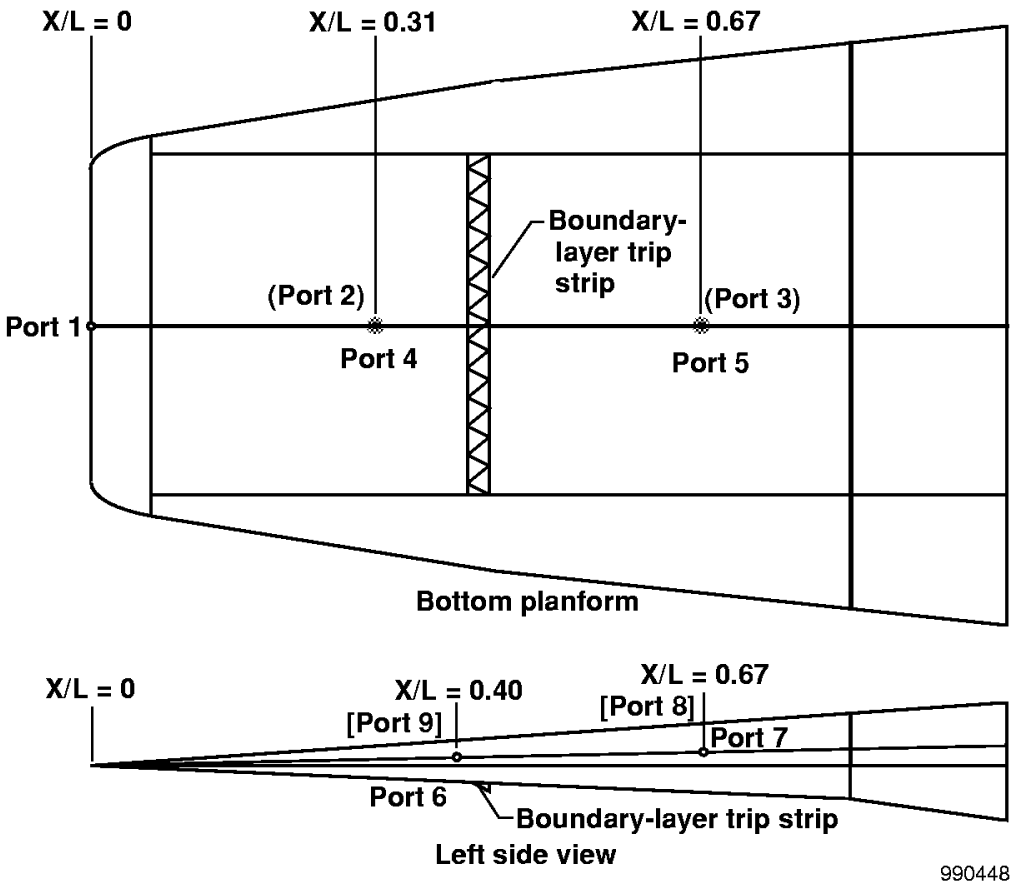

Figure 1. Test article pressure port locations.

\section{Pressure Transducers}

The nine pressures are sensed using a combination of absolute and differential precision pressure transducers (PPTs). Figure 2 shows the pneumatic layout of these sensors. Differences between the pairs of upper and lower ramp surface pressures (ports 2 and 4; ports 3 and 5) are sensed by differential pressure transducers to provide high accuracy and a high-resolution measurement for use by the real-time algorithm. Each differential pair is also "teed" to an absolute pressure transducer that allows the absolute pressure level at each port to be sensed or calculated. The forebody side ports (ports 6 and 8; ports 7 and 9), although not used by the real-time algorithm, are sensed in a similar manner. The single stagnation pressure (port 1) is sensed using an absolute sensor.

All of the pressure transducers have serial digital outputs, which are connected through an individually addressable, multidrop RS-485 bus. The sensors also provide an optional analog output. The PPT digital output is the primary signal used in the real-time and postflight algorithms. The analog signal 

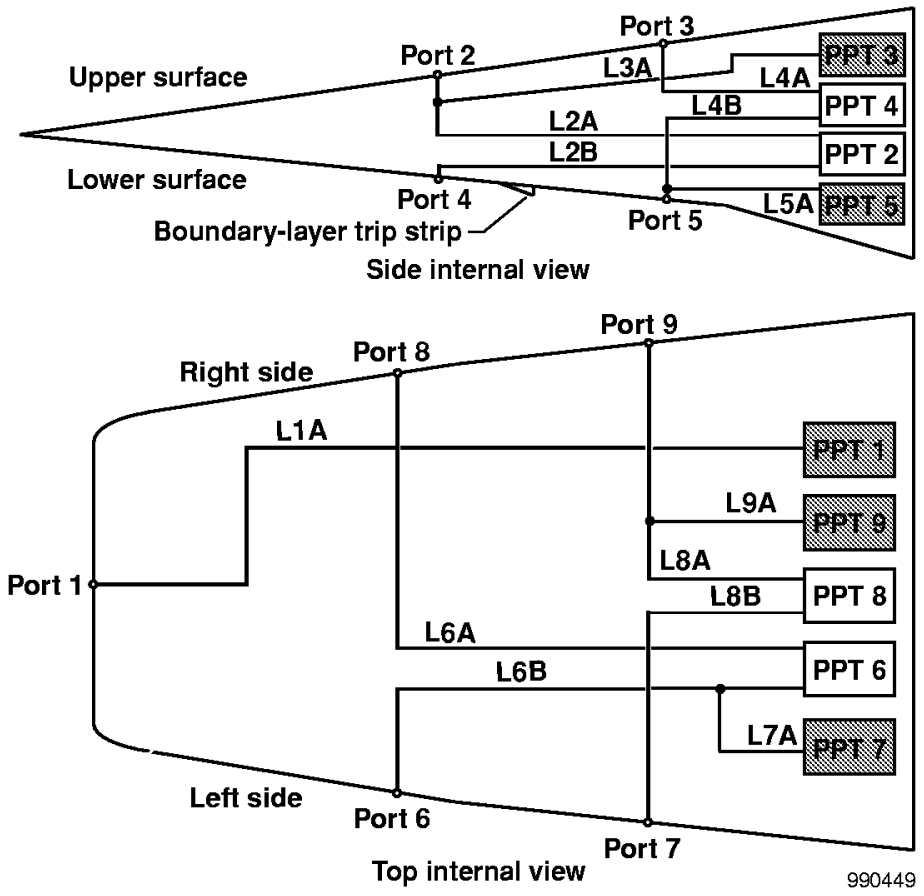

Figure 2. Wind-tunnel model pressure transducer connectivities.

is recorded only for postflight analysis and provides data redundancy if the digital signal fails. The pressure transducers use a piezo-resistive bridge technology and have a built-in digital temperature compensation over a range from -40 to $80^{\circ} \mathrm{C}$.

The manufacturer's specified accuracy for the sensor output for both digital and analog is 0.05 percent of full scale (ref. 9). Laboratory tests conducted at the NASA Dryden Flight Research Center (Edwards, California) have shown the sensors to be accurate to within 0.025 percent of the fullscale value. Table 1 shows the types of sensors used in this design and the sensor full-scale ranges. The sensors used as a part of the real-time system architecture are indicated with an asterisk.

\section{Pneumatic Layout}

Table 2 shows the line lengths, tubing diameters, and entrapped volumes for the various pneumatic components (fig. 2). The effective volume in table 2 also includes the entrapped volume of the pneumatic fittings and the transducer volumes. Results from preliminary oblique shock theory (ref. 10) and engineering judgment were used in the placement of the pressure ports on the vehicle. The pressure port size on the upper and lower ramp surfaces was 0.04-in. diameter. The pressure port size on the leading edge and sides of the vehicle had a diameter of $0.02 \mathrm{in}$. to limit stagnation heating effects. All ports were drilled normal to the surface.

The "teed" pneumatic lines required to obtain the absolute pressure levels for ports 3 and 5 and ports 6 and 8 are a cause for concern because of latencies that may be introduced into the sensed pressure signals. These latencies are especially critical for the real-time sensing system. The effects of these latencies will be analyzed in detail in the Results and Discussion section. 
Table 1. Sensor type at each port location.

\begin{tabular}{lcccc}
\hline \hline $\begin{array}{c}\text { Sensor } \\
\text { identification }\end{array}$ & Port & $\begin{array}{c}\text { Parameter } \\
\text { sensed }\end{array}$ & $\begin{array}{c}\text { Sensor } \\
\text { type }\end{array}$ & $\begin{array}{c}\text { Range, } \\
\text { lbf/in }\end{array}$ \\
\hline PPT 1 & 1 & $\begin{array}{c}\text { Total } \\
\text { pressure }\end{array}$ & Absolute & $0-15$ \\
PPT 2* & 2,4 & $\alpha$ & Differential & \pm 5 \\
PPT 3* & 2 & $\alpha$ & Absolute & $0-15$ \\
PPT 4* & 3,5 & $\alpha$ & Differential & \pm 5 \\
PPT 5* & 5 & $\alpha$ & Absolute & $0-15$ \\
PPT 6 & 6,8 & $\beta$ & Differential & \pm 5 \\
PPT 7 & 6 & $\beta$ & Absolute & $0-15$ \\
PPT 8 & 7,9 & $\beta$ & Differential & \pm 5 \\
PPT 9 & 9 & $\beta$ & Absolute & $0-15$ \\
\hline \hline
\end{tabular}

Table 2. Pneumatic layout characteristics.

\begin{tabular}{lccc}
\hline \hline $\begin{array}{c}\text { Line } \\
\text { number }\end{array}$ & $\begin{array}{c}\text { Line } \\
\text { length, in. }\end{array}$ & $\begin{array}{c}\text { Tube } \\
\text { diameter, in. }\end{array}$ & $\begin{array}{c}\text { Volume, } \\
\mathrm{in}^{3}\end{array}$ \\
\hline L1A & 84 & 0.063 & 0.3502 \\
L2A & 45 & 0.063 & 0.2381 \\
L2B & 37 & 0.063 & 0.2049 \\
L3A & 44 & 0.063 & 0.2340 \\
L4A & 16 & 0.063 & 0.1176 \\
L4B & 25 & 0.063 & 0.1550 \\
L5A & 24 & 0.063 & 0.1509 \\
L6A & 36 & 0.063 & 0.2007 \\
L6B & 38 & 0.063 & 0.2090 \\
L7A & 37 & 0.063 & 0.2049 \\
L8A & 36 & 0.063 & 0.2007 \\
L8B & 24 & 0.063 & 0.1509 \\
L9A & 35 & 0.063 & 0.1966 \\
\hline \hline
\end{tabular}




\section{WIND-TUNNEL FACILITIES, EQUIPMENT, TEST CONDITIONS, AND PROCEDURES}

A series of wind-tunnel experiments was conducted to evaluate the FADS system. The basic measurement systems were evaluated over a broad range of Mach numbers, and a data set allowing a preliminary airdata calibration was obtained.

\section{Facilities}

All wind-tunnel testing occurred at the Arnold Engineering Development Center (Arnold Air Force Base, Tennessee) Von Karman Facility in tunnels A and B. Tunnel A is a 40- by 40-in., continuous, closed-circuit, variable-density, supersonic wind tunnel with a Mach number range of 1.5 to 5.5. The tunnel is served by a main compressor system that provides a wide range of mass flow and stagnation pressures to a maximum of $195 \mathrm{lbf} / \mathrm{in}^{2}$ absolute (ref. 11).

Tunnel B is a continuous, closed-circuit, hypersonic wind tunnel with a 50-in.-diameter test section. Tunnel B uses two axisymmetric, contoured nozzles that provide two fixed Mach numbers of 6 and 8 with an operating pressure range of 20 to $300 \mathrm{lbf} / \mathrm{in}^{2}$ absolute at Mach 6 and 50 to $900 \mathrm{lbf} / \mathrm{in}^{2}$ absolute at Mach 8 (ref. 11).

\section{Wind-Tunnel Test Equipment}

Figure 3 shows the internal layout of the test article with nine PPTs and one inclinometer. The sensors were enclosed in cooling jackets to ensure that the sensor operating limits were not exceeded during the test. An inclinometer measured the model incidence angle over a range of $\pm 14.5^{\circ}$ with an accuracy of 0.02-percent full scale. The model used in the test was an 80-percent-scale model of the SCRamjet test vehicle forebody and was designed for hypersonic testing for extended periods. The model was milled from solid bar stock of heat-treated and solution-annealed 316 stainless steel (ref. 12) and had a boundary-layer trip strip installed just aft of pressure port 4 (fig. 1). The wind-tunnel pneumatic system was designed to duplicate the flight hardware.

Analog and digital outputs from the PPTs were sensed during the wind-tunnel tests. Digital data were polled from all PPTs at a rate of 48.8 samples/sec. Analog data were obtained using a 16-bit analog-todigital converter unit controlled by the wind-tunnel computer. Figure 4 shows a schematic of the data acquisition system used for the wind-tunnel tests. Figures 5 and 6 show the model as mounted in tunnels $\mathrm{A}$ and $\mathrm{B}$ for testing.

\section{Wind-Tunnel Test Procedures and Conditions}

Wind-tunnel data were taken during constant angles of attack and sideslip and during pitch-pause runs with sweeps in angles of attack and sideslip. Data were obtained over a Mach number range of 3 to 8 , an angle-of-attack range of $-6^{\circ}$ to $12^{\circ}$, and an angle-of-sideslip range of $\pm 3^{\circ}$. In the pitch-pause

maneuvers, data were obtained in 1-deg increments. Angle-of-sideslip data were obtained in 0.5-deg increments. The dwell time at each pitch-pause data point was approximately $15 \mathrm{sec}$. Table 3 shows the wind-tunnel conditions. 


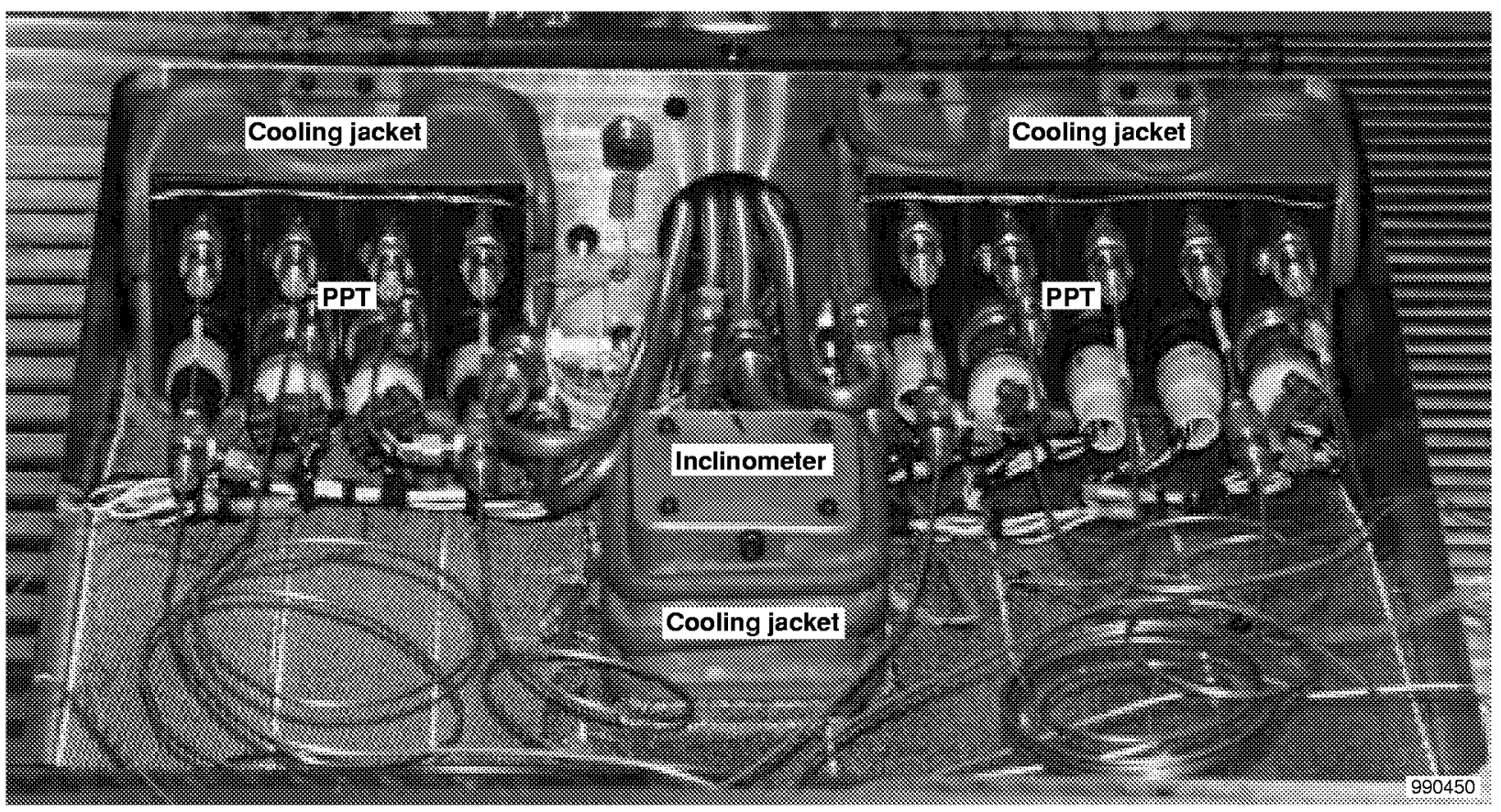

Figure 3. Internal layout of wind-tunnel model.

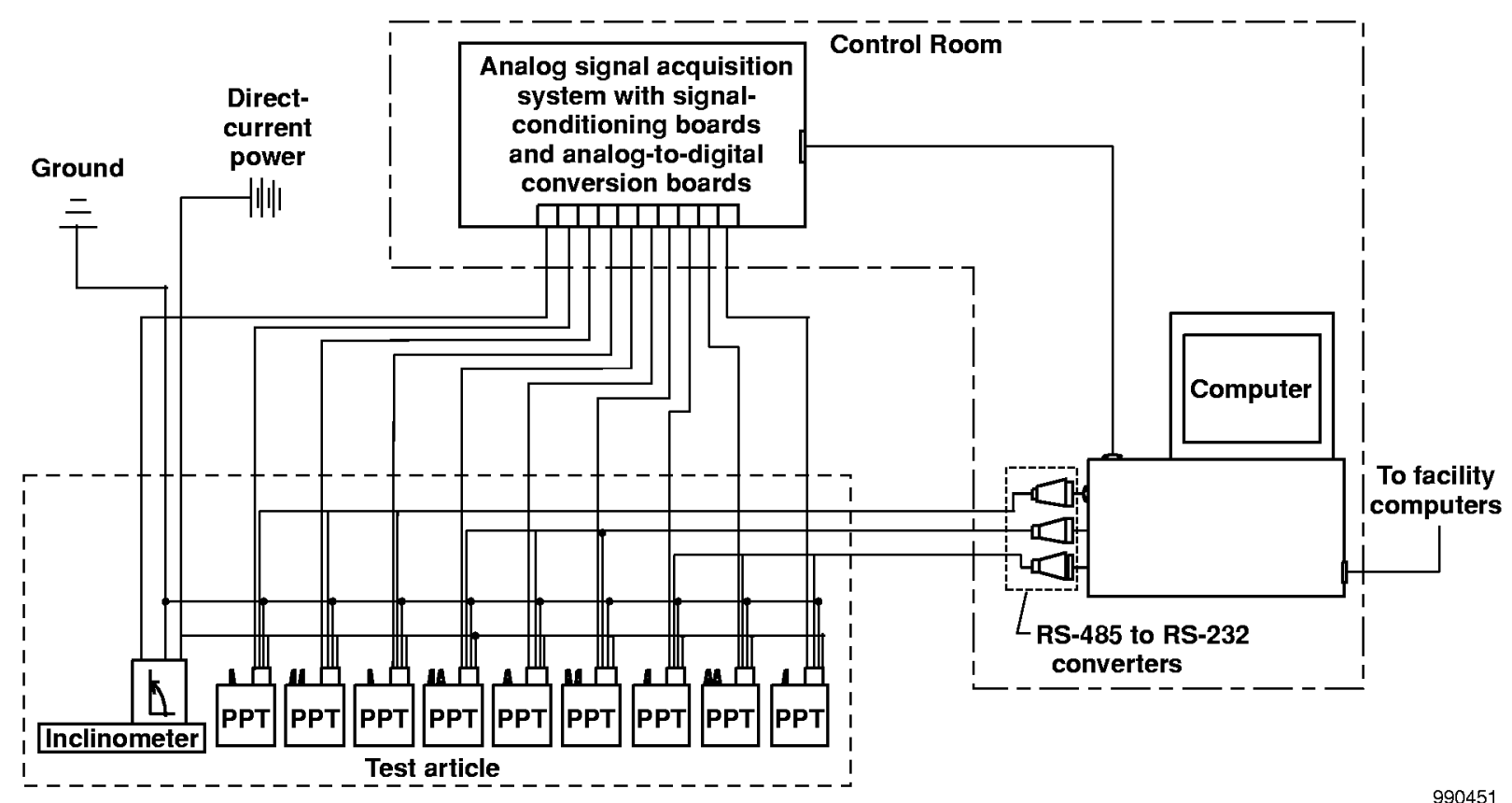

Figure 4. Wind-tunnel test setup. 


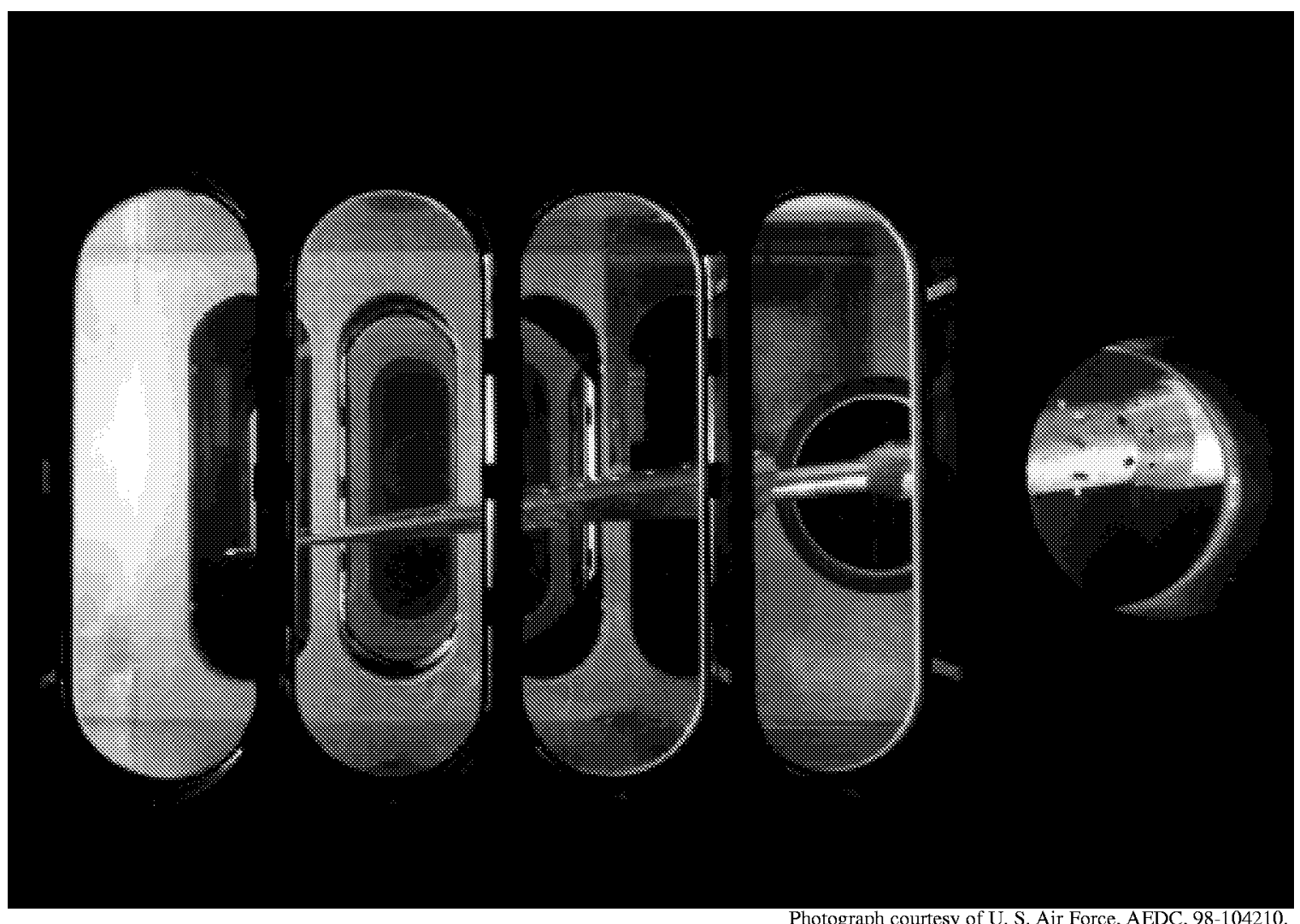

Figure 5. Test article in Tunnel A test section.

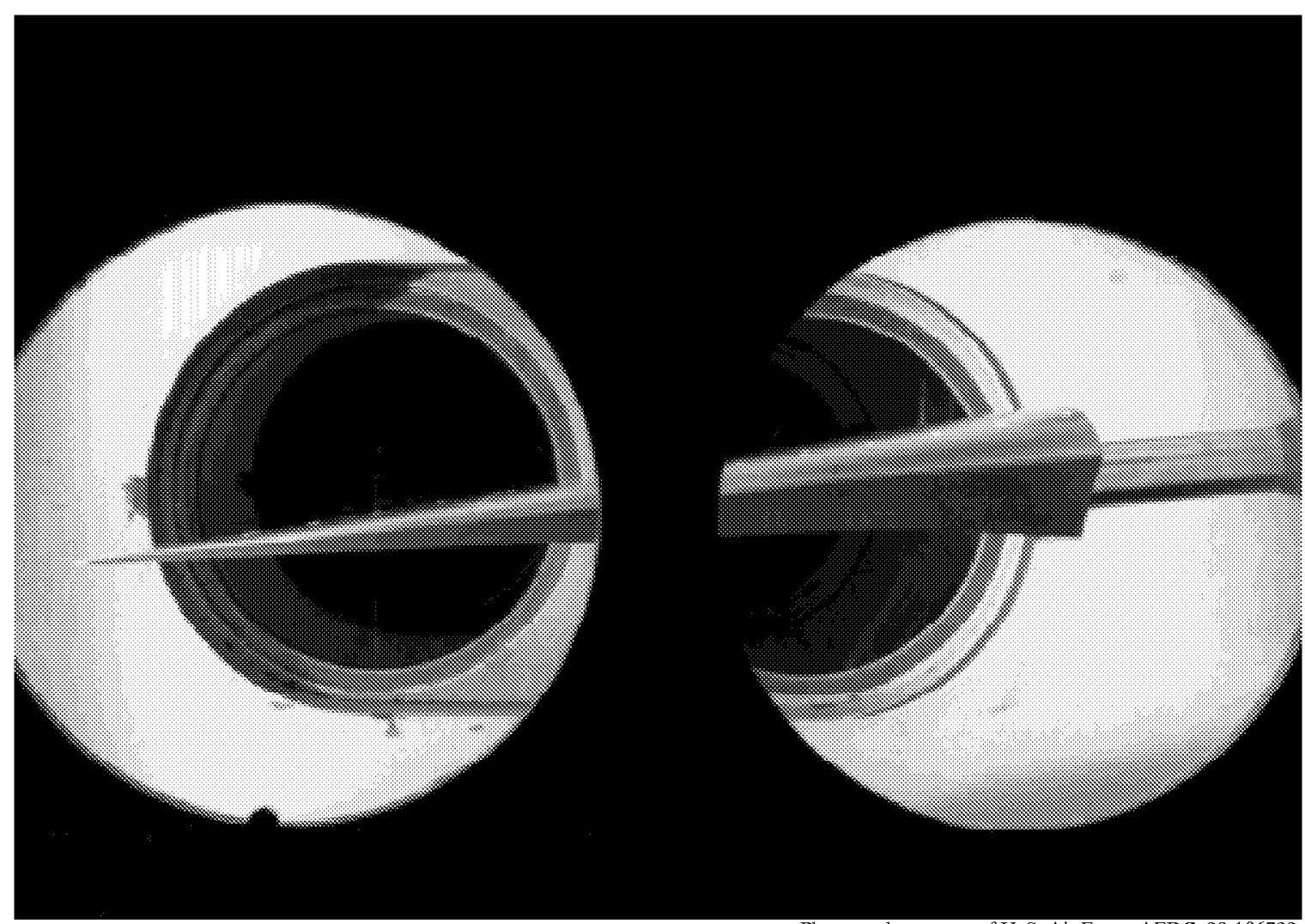

Photograph courtesy of U. S. Air Force, AEDC, 98-106729.

Figure 6. Test article in Tunnel B test section. 
Table 3. Wind-tunnel test summary.

\begin{tabular}{lcc|c|c|c}
\hline \hline Test condition & $\begin{array}{c}\text { Mach number } \\
\text { s }\end{array}$ & Remark & 5 & $\begin{array}{c}\text { Reynolds number, } \\
\text { mil/ft }\end{array}$ \\
\hline$\beta$ sweep at $-6^{\circ} \alpha$ & $\times \times \times \times \times$ & Basic & 3.00 \\
$\beta$ sweep at $-4^{\circ} \alpha$ & $\times \times \times \times \times$ & Basic & 3.00 \\
$\beta$ sweep at $-2^{\circ} \alpha$ & $\times \times \times \times \times$ & Basic & 3.00 \\
$\beta$ sweep at $0^{\circ} \alpha$ & $\times \times \times \times \times$ & Basic & 3.00 \\
$\beta$ sweep at $2^{\circ} \alpha$ & $\times \times \times \times \times$ & Basic & 3.00 \\
$\beta$ sweep at $4^{\circ} \alpha$ & $\times \times \times \times \times$ & Basic & 3.00 \\
$\beta$ sweep at $6^{\circ} \alpha$ & $\times \times \times \times \times$ & Basic & 3.00 \\
$\beta$ sweep at $8^{\circ} \alpha$ & $\times \times \times \times \times$ & Basic & 3.00 \\
$\beta$ sweep at $10^{\circ} \alpha$ & $\times \times \times \times \times$ & Basic & 3.00 \\
$\beta$ sweep at $12^{\circ} \alpha$ & $\times \times \times \times \times$ & Basic & 3.00 \\
$\alpha$ sweep at $0^{\circ} \beta$ & $\times \times \times \times \times$ & Hysteresis/Lag effects & 3.00 \\
$\alpha$ sweep at $3^{\circ} \beta$ & $\times \times \times \times \times$ & Hysteresis/Lag effects & 3.00 \\
$\alpha$ sweep at $0^{\circ} \beta$ & $\times \times \times \quad$ & Reynolds number effects & 1.80 \\
$\alpha$ sweep at $3^{\circ} \beta$ & $\times \times \times \quad$ & Reynolds number effects & 1.80 \\
$\alpha$ sweep at $0^{\circ} \beta$ & & $\times \times$ & Reynolds number effects & 3.76 \\
$\alpha$ sweep at $3^{\circ} \beta$ & & $\times \times$ & Reynolds number effects & 3.76 \\
\hline \hline
\end{tabular}




\section{REAL-TIME ANGLE-OF-ATTACK ESTIMATION ALGORITHM}

The primary function of the real-time angle-of-attack estimation algorithm is to provide a pneumatically based, measurement estimate of the bias in the INS-derived angle of attack. The real-time FADS algorithm is composed of two basic routines, FADS calibration and signal selection. These algorithms require Mach number, which is provided by the INS. At relatively high velocities, inertial Mach number is sufficiently accurate when used with a representative atmospheric model.

For the sensor configuration shown in figure 2, only three unique angle-of-attack estimates are available, although four pressure ports and four pressure sensors are designated for real-time angle-ofattack estimation. The individual angle-of-attack measurements are as follows:

$$
\begin{aligned}
& F A D S_{\alpha_{1}}=\left[\frac{\left(P_{P P T ~ 2}\right)}{\bar{q}}\right] \mathrm{C}_{\mathrm{PPT} 2} \\
& F A D S_{\alpha_{2}}=\left[\frac{\left(P_{P P T ~ 4}\right)}{\bar{q}}\right] \mathrm{C}_{\mathrm{PPT} 4} \\
& F A D S_{\alpha_{3}}=\left[\frac{\left(\mathrm{P}_{P P T 5}-\mathrm{P}_{P P T ~ 3}\right)}{\bar{q}}\right] \mathrm{C}_{\text {PPT 53 }},
\end{aligned}
$$

where $F A D S_{\alpha_{1}}$ is the forward angle-of-attack estimate, $F A D S_{\alpha_{2}}$ is the rear angle-of-attack estimate, and $F A D S_{\alpha_{3}}$ is the pseudodifferential angle-of-attack estimate.

Figure 7 shows the angle-of-attack estimation algorithm in block diagram form. For PPT 2, PPT 4, and the difference between PPT 3 and PPT 5, a calibration curve of differential pressure as a function of angle of attack for each Mach number is required. These steady-state calibration curves were initially predicted using engineering methods, then refined with wind-tunnel data. The block diagram in figure 7 shows these calibration curves implemented as two-dimensional table lookups.

The sensor selection routine is used to determine out-of-range or "failed" FADS sensors. Because the flight control system is single-string, the INS angle of attack is assumed to be an unfailed but biased estimate of true angle of attack. The INS angle of attack is passed through a first-order lag filter corresponding to each FADS angle-of-attack pneumatic lag model derived from wind-tunnel data. (This model will be described in the Results and Discussion section.) These lagged INS angle-of-attack signals are then compared to the three corresponding FADS angle-of-attack signals. A FADS angle-of-attack signal is considered "failed" if this comparison exceeds a threshold for a fixed length of time. The threshold is a function of Mach number and is dependent on the amount of lag that can be tolerated by the system.

The final FADS angle of attack is the average of the "unfailed" signals. This final FADS angle of attack is then used to bias the INS angle of attack through a first-order filter as shown in figure 7. If all FADS sensors are declared failed, the bias will fade to 0 and the uncompensated INS angle of attack is used in the flight control laws.

Other significant airdata parameters sensed by the FADS system are derived from postflight data using nonlinear regression algorithms. Reference 1 details how these postflight airdata estimation algorithms are developed. 


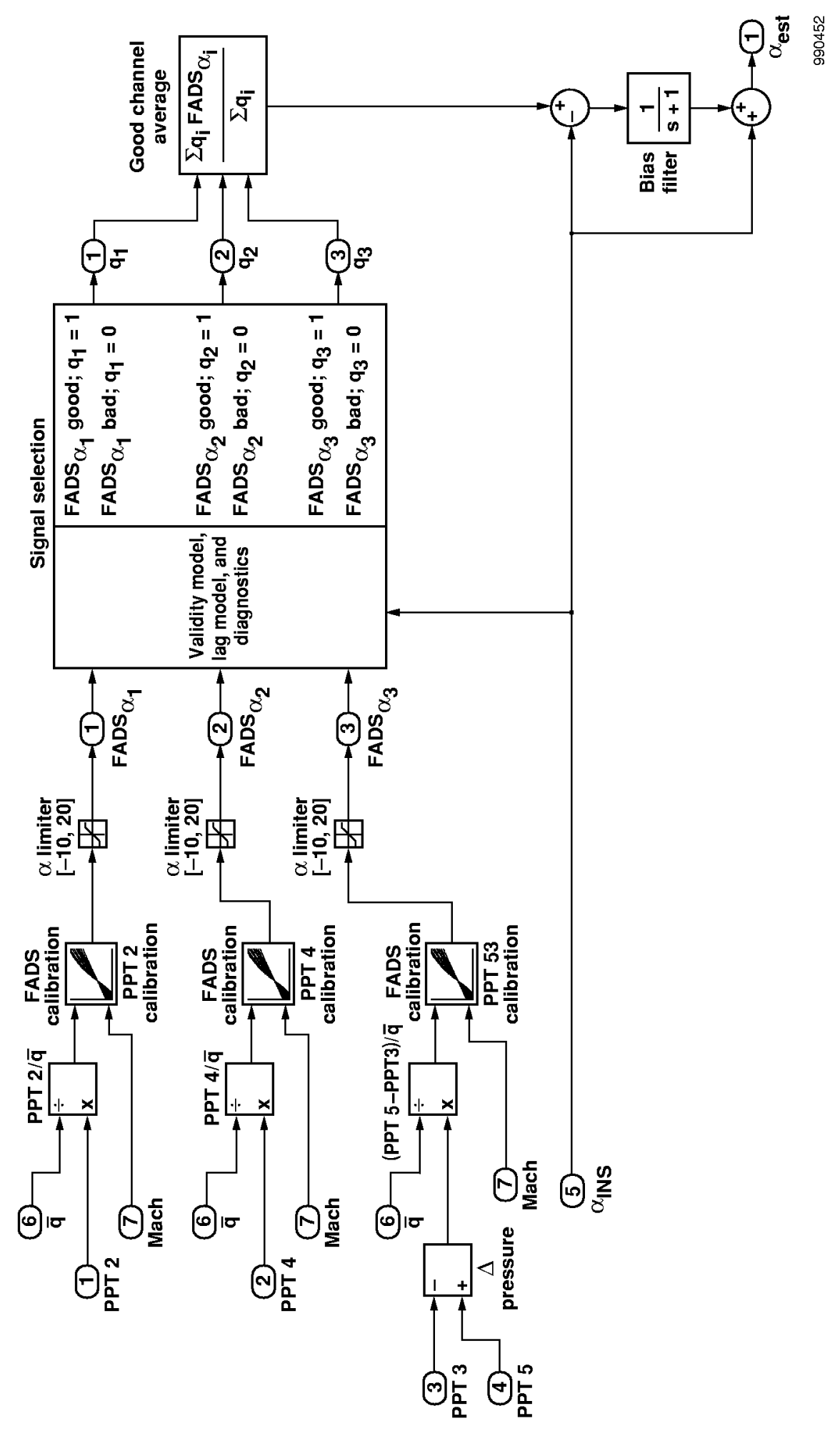

Figure 7. $\alpha_{F A D S}$ and $\alpha_{I N S}$ estimation and integration block diagram. 


\section{RESULTS AND DISCUSSION}

Steady-state pressure and pneumatic lag data were obtained in the wind-tunnel test series. Results are compared with both predicted static pressure and simulated pneumatic lag results in the following subsections.

\section{Steady-State Pressure}

The calibration curves used to derive angle of attack from the pressure data were initially developed using engineering analysis. Newtonian flow theory was used to obtain stagnation pressure. Oblique shock theory or Prandtl-Meyer expansion methods (ref. 10), depending on angle-of-attack and flow conditions on the wedge, were used to solve for surface pressures on the wedge itself. Because of coding methods, a small jump in the data occurs only for the Mach 3 case at an angle of attack equal to the wedge angle (figs. 8 (a)-(d)). A wind-tunnel test was then conducted to validate the initial pressure model of the FADS system.

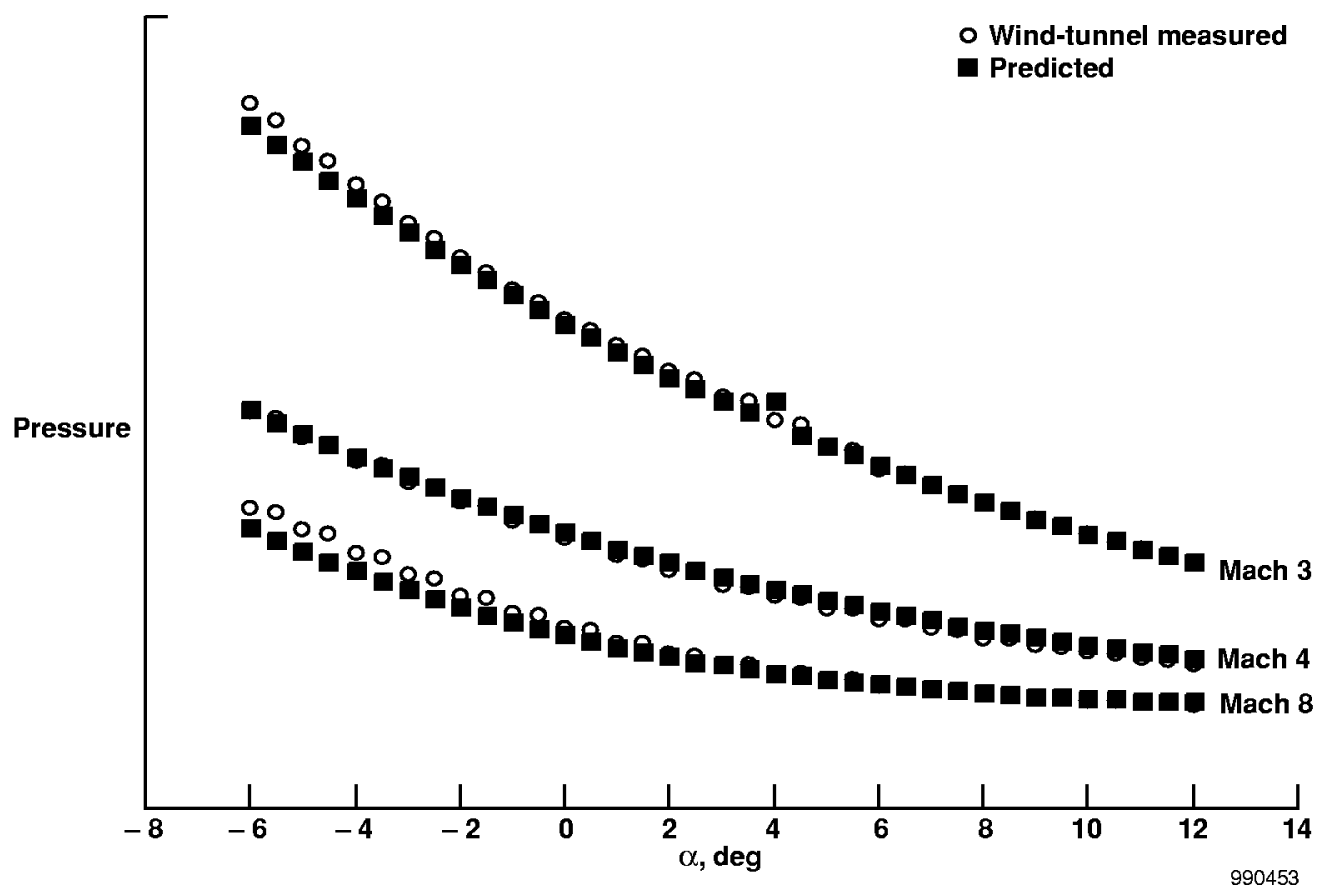

(a) Pressure as a function of angle of attack for port 2.

Figure 8. Comparison of empirical and wind-tunnel data for the $\alpha_{F A D S}$. 


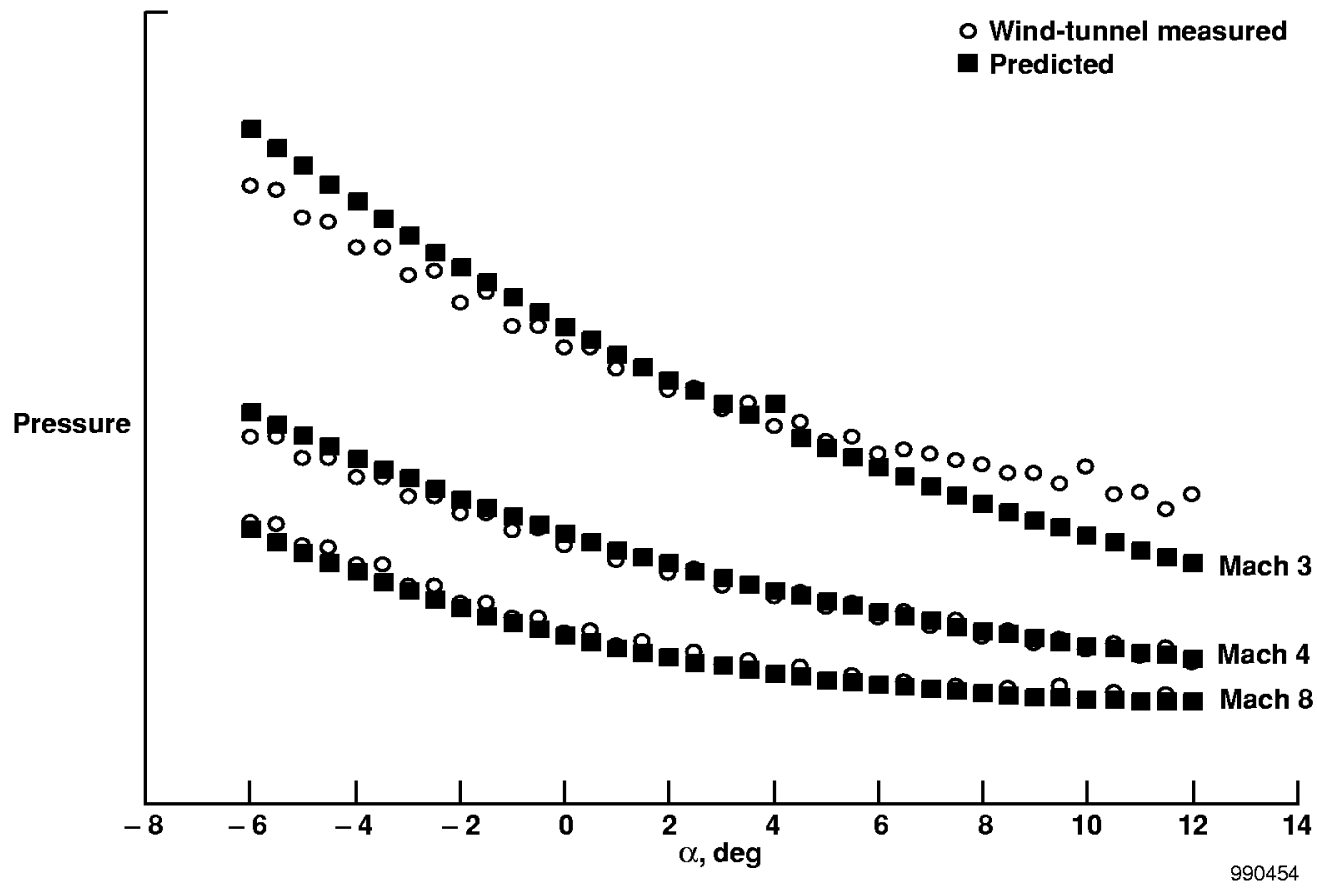

(b) Pressure as a function of angle of attack for port 3 .

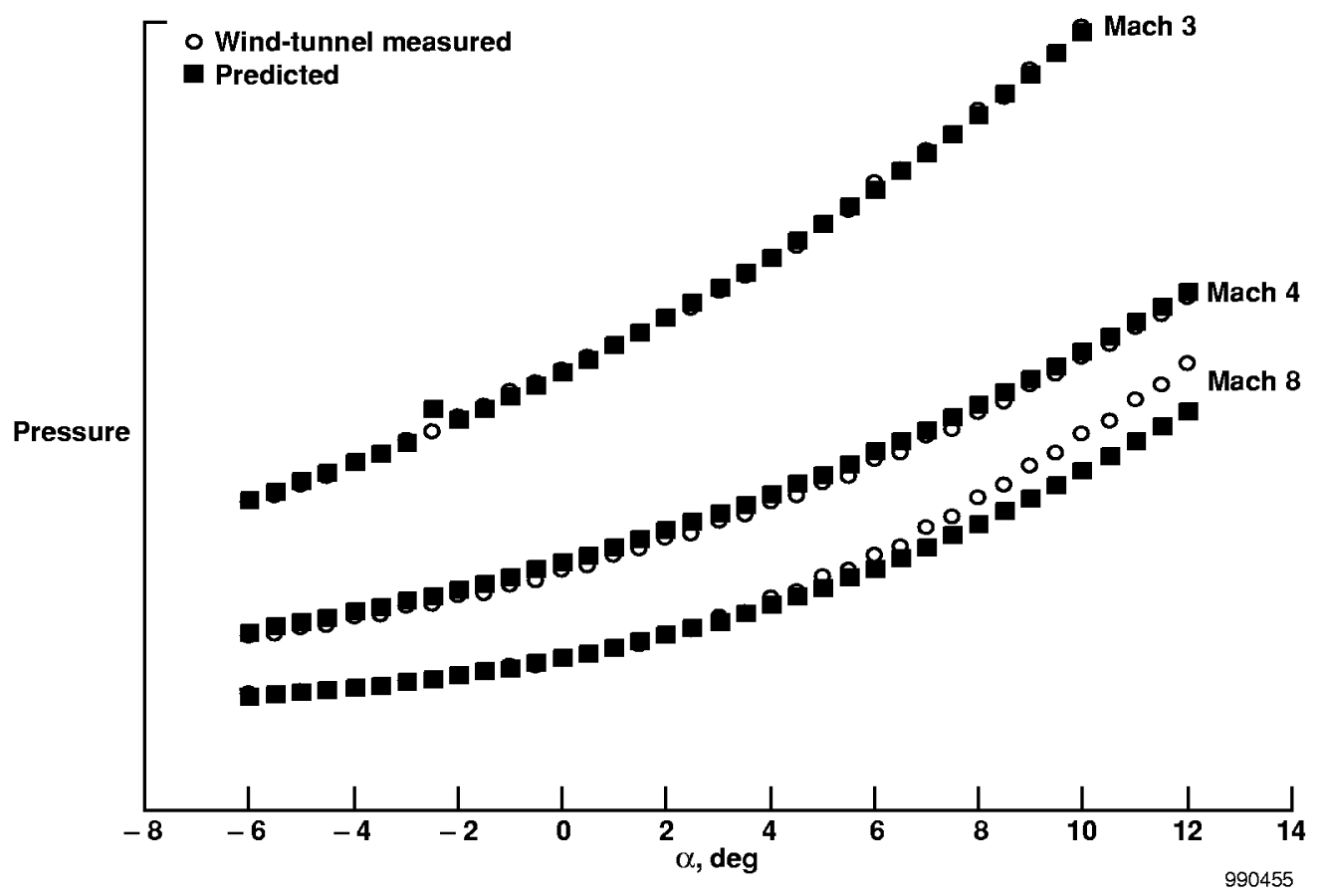

(c) Pressure as a function of angle of attack for port 4 .

Figure 8. Continued. 


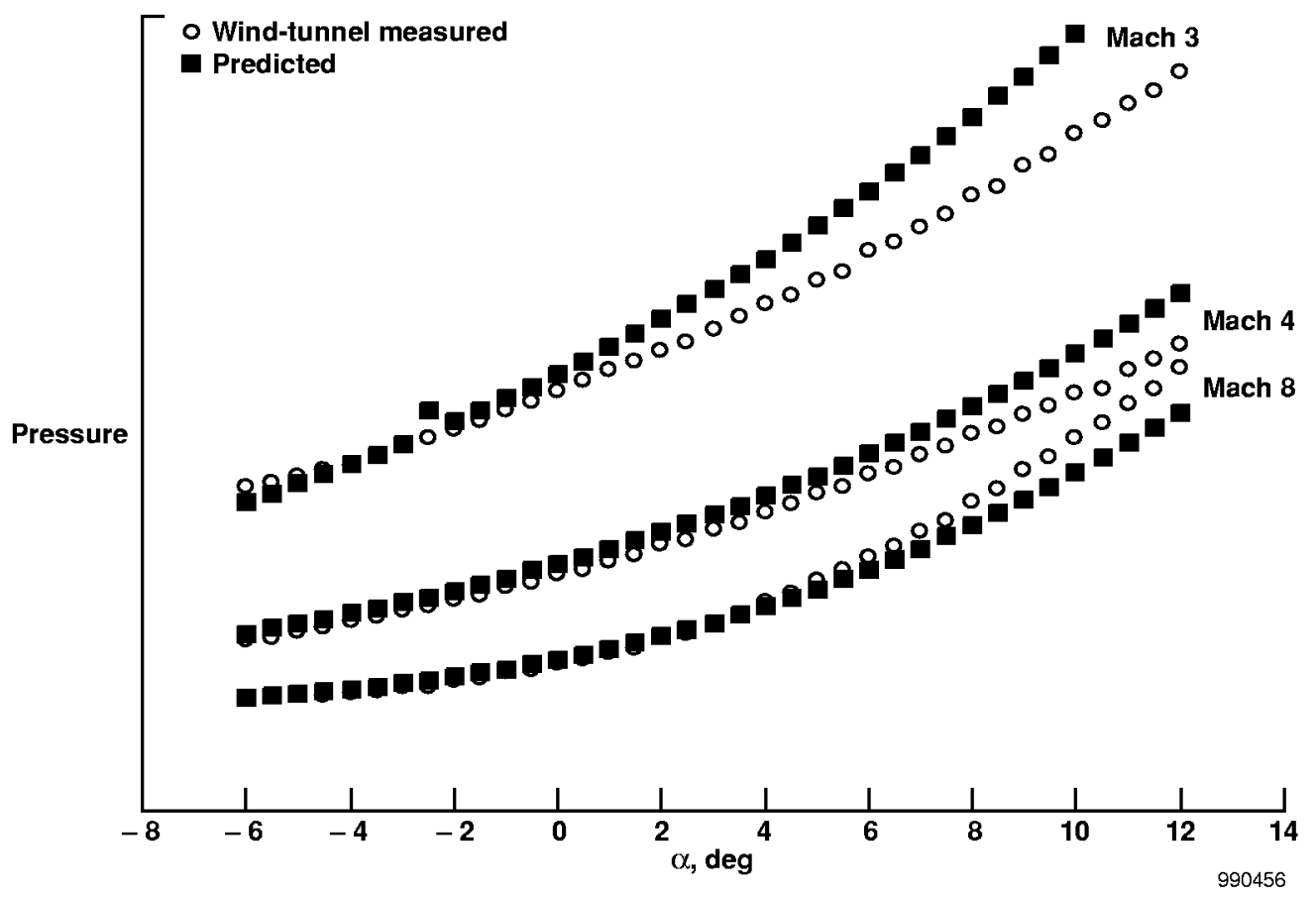

(d) Pressure as a function of angle of attack for port 5.

Figure 8. Concluded.

Figures 8(a)-(d) show the comparison of the predicted pressure model and the wind-tunnel data as a function of angle of attack for Mach numbers of 3,4, and 8. The wind-tunnel data are shown as open symbols and the predicted data are shown as solid symbols. Results for the other Mach numbers listed in table 3 are similar to the Mach 8 results.

Results from port 2 (fig. 8(a)) indicate that the predicted pressures compare very well with the wind-tunnel pressures. Results from port 4 (fig. 8(c)) indicate similar results; the exception is the Mach 8 case in which pressure for the high angles of attack was underpredicted. This slight underprediction may be caused by flow separation at the high Mach numbers.

The two rear ports (ports 3 and 5) show large differences, especially on the lower ramp port 5 (fig. 1). The results for port 3 (fig. 8(b)) indicate good agreement, except for the Mach 3 case in which a small slope change appears in the wind-tunnel results. The cause for this difference is unknown, but may be because of data acquisition errors. The results for port 5 (fig. 8(d)) indicate an overprediction of the pressures at the high angles of attack at Mach 3 and 4 and an underprediction at Mach 8. This difference is most likely caused by the presence of the boundary-layer trip strip located in front of port 5 . The simple prediction models used for the wind-tunnel comparisons could not include a boundary-layer trip strip. The boundary-layer trip strip was installed on the model in a manner similar to that planned for the flight vehicle. Overall, the predicted pressures compared well with the wind-tunnel pressures for ports located forward of the boundary-layer trip strip. Additional corrections for boundary-layer trip strip effects could be developed for port 5 to reduce the errors even further. 
Pressure data obtained from the wind-tunnel test were used as input to the angle-of-attack estimation routines previously described (fig. 7). True angle of attack and tunnel dynamic pressure were used as inputs instead of the INS parameters that will be used in the flight software. Figure 9 shows angle-ofattack error $\left(\alpha_{\text {true }}-\alpha_{\text {FADS }}\right)$ across the angle-of-attack range for the same Mach numbers as shown in figure 8. Figure 9(a) shows the angle-of-attack error for the forward pair of ports, and figure 9(b) shows the angle-of-attack error for the aft pair of ports.

The angle-of-attack error shown for the forward ports generally is less than $0.2^{\circ}$ at less than $6^{\circ}$ angle of attack, and is less than $0.5^{\circ}$ across the entire angle-of-attack envelope. These excellent results are consistent with the pressure results shown in figures 8(a) and 8(c). The results for the aft pair of ports (fig. 9(b)) show larger angle-of-attack errors than the forward pair of ports, especially at the high angles of attack. The trends in angle-of-attack error are consistent with the errors in predicted pressures shown in figures $8(\mathrm{~b})$ and $8(\mathrm{~d})$. The results show the viability of the real-time angle-of-attack estimation method.

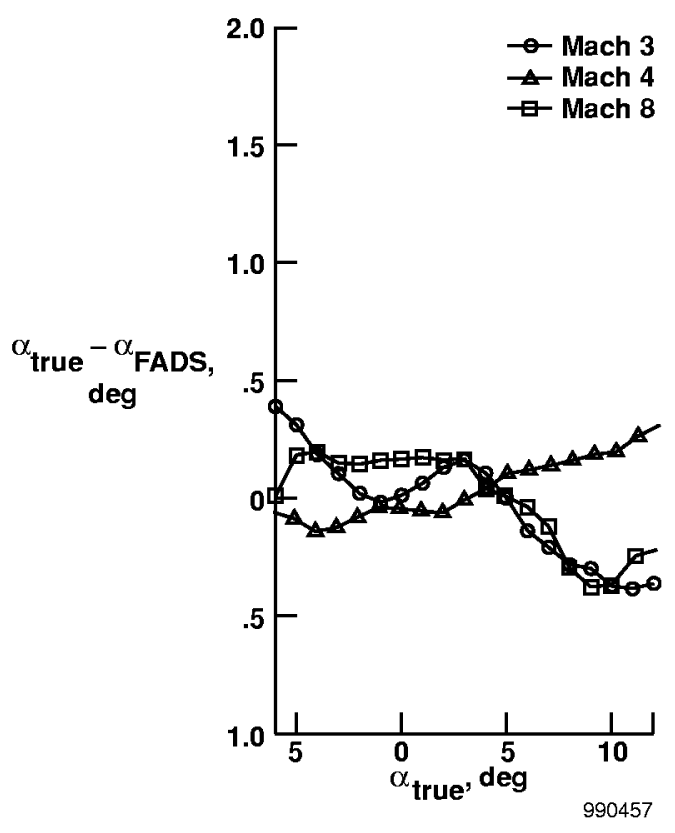

(a) Forward ports $\left(F A D S_{\alpha_{1}}\right)$.

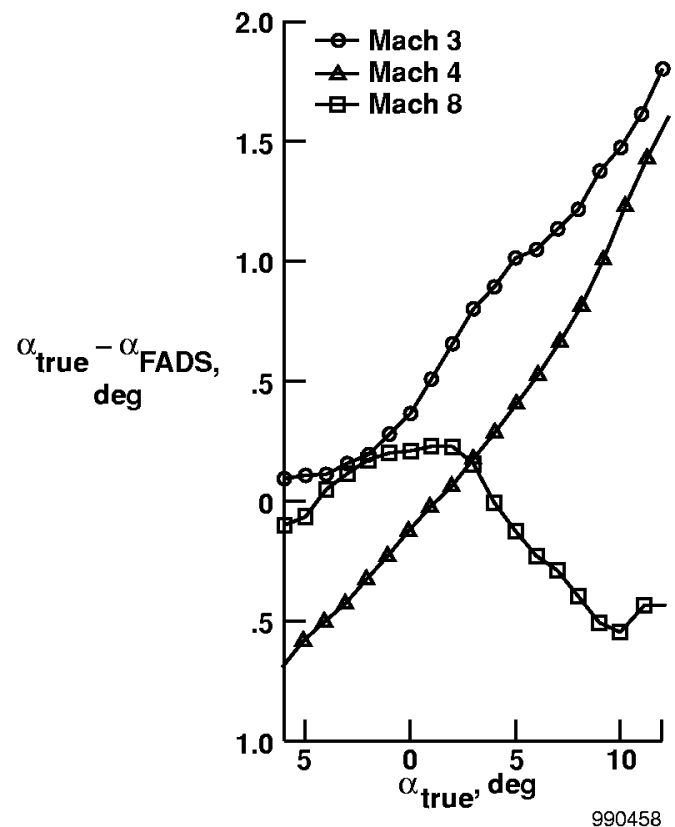

(b) Aft ports $\left(F A D S_{\alpha_{2}}\right.$ and $\left.F A D S_{\alpha_{3}}\right)$.

Figure 9. Angle-of-attack error $\left(\alpha_{\text {true }}-\alpha_{F A D S}\right)$ as a function of true angle of attack.

\section{Pneumatic Lag}

Because the FADS system is pneumatically based, pressure lags must be taken into account. For the current angle-of-attack estimation design, pneumatic lag models are used in the sensor selection routine to determine out-of-range or "failed" FADS sensors. A pressure lag model was developed for each port (or pair of ports) in the system because tubes of different length were used for each sensor (figs. 1-2 and table 2). The pressure lag from each port to sensor was modeled as a first-order lag (ref. 13):

$$
\frac{P_{P P T}}{P_{\text {port }}}=\frac{k}{s+k},
$$


where $k$ is a nonlinear function of the measurement geometry and the input pressure $P_{\text {port }}$. The lag constant, $k$, can be represented by the following form:

$$
k=\frac{1}{\tau}=\frac{P_{\text {port }}}{\mu}\left[\frac{g \pi D^{4}}{128 L V_{e}}\right] \text {, }
$$

where $D$ is the diameter of the tube, $L$ is the tube length, and $V_{e}$ is the effective volume. Equations (2) and (3) characterize the lag from a single port to an absolute pressure measurement.

Figure 10 shows wind-tunnel data from a Mach 6, dynamic, pitch-pause angle-of-attack sweep ( $-6^{\circ}$ to $12^{\circ}$ ). As seen in the absolute pressure measurements (PPT 3 and PPT 5), the lag characteristics change significantly over the pressure range as predicted by equation (3). In contrast, the lag characteristic of the differential pressure transducer from a pair of ports (PPT 2) remains relatively constant across the pressure range. This empirical observation allows the differential pressure lags to be adequately characterized by equation (2) with a constant lag factor across the measurement range. In other words, the lag model for a pair of ports to a differential pressure measurement is only a function of Mach number and not a function of the input pressure, thus greatly simplifying the lag characterization.

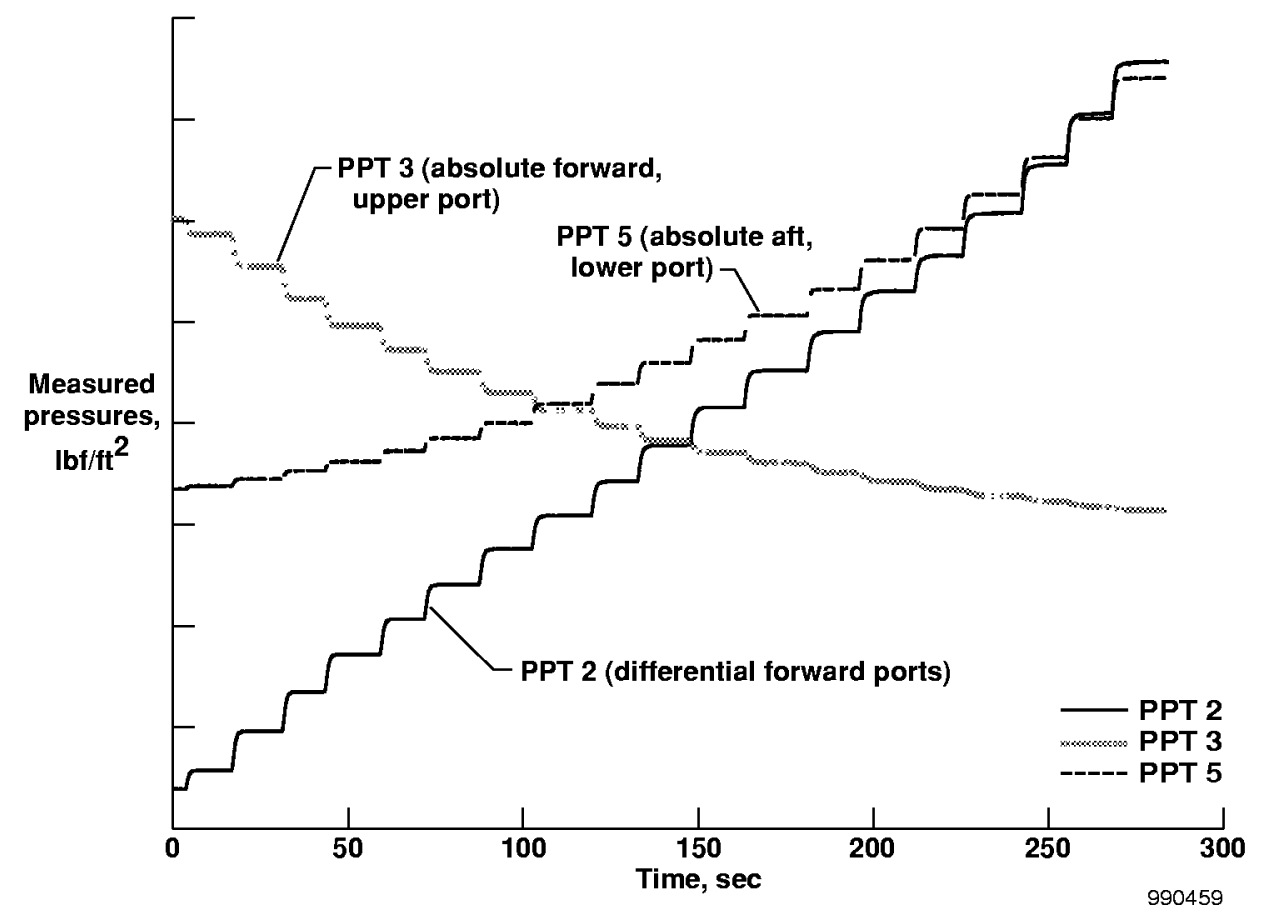

Figure 10. Typical wind-tunnel pitch-pause angle-of-attack sweep for Mach 6.

An analog matching technique was used to estimate the lag constant for the differential pressure signals across the angle-of-attack measurement range. True angle of attack was converted to unlagged pressure by using the reverse angle-of-attack estimation algorithm shown in figure 7 . The resulting pressure was then used as an input to a constant first-order lag model to obtain the simulated pressure at the PPT. The lag constant was varied in order to minimize the error between the lagged results and the actual differential pressure signal, and thus to obtain the best fit over the entire range. 
Figures 11(a) and 11(b) show typical results for one of the pitch-pause angle-of-attack sweeps (at Mach 6) for both an absolute and a differential transducer. Figure 11(a) shows a time history of scaled true angle of attack with the actual and simulated absolute pressure for the forward upper port (PPT 3). Figure 11(b) shows a time history of scaled true angle of attack with actual and simulated differential pressure between the forward pair of ports (PPT 2). Three sections of the time history are magnified with equal time segments shown (figs. 11(a)-(b)). In figure 11(a), the magnified time history shows the nonlinear, second-order lag characteristic of the absolute pressure measurement. In figure 11(b), the lag characteristics shown in the magnified time histories are nearly identical across the measurement range. Both figures 11(a) and 11(b) show very good agreement between the simulated and actual signals, especially in the low-angle-of-attack range. The results in figure 11(b) show that the pneumatics lags can be characterized by a first-order lag in which the lag constant is only a function of Mach.

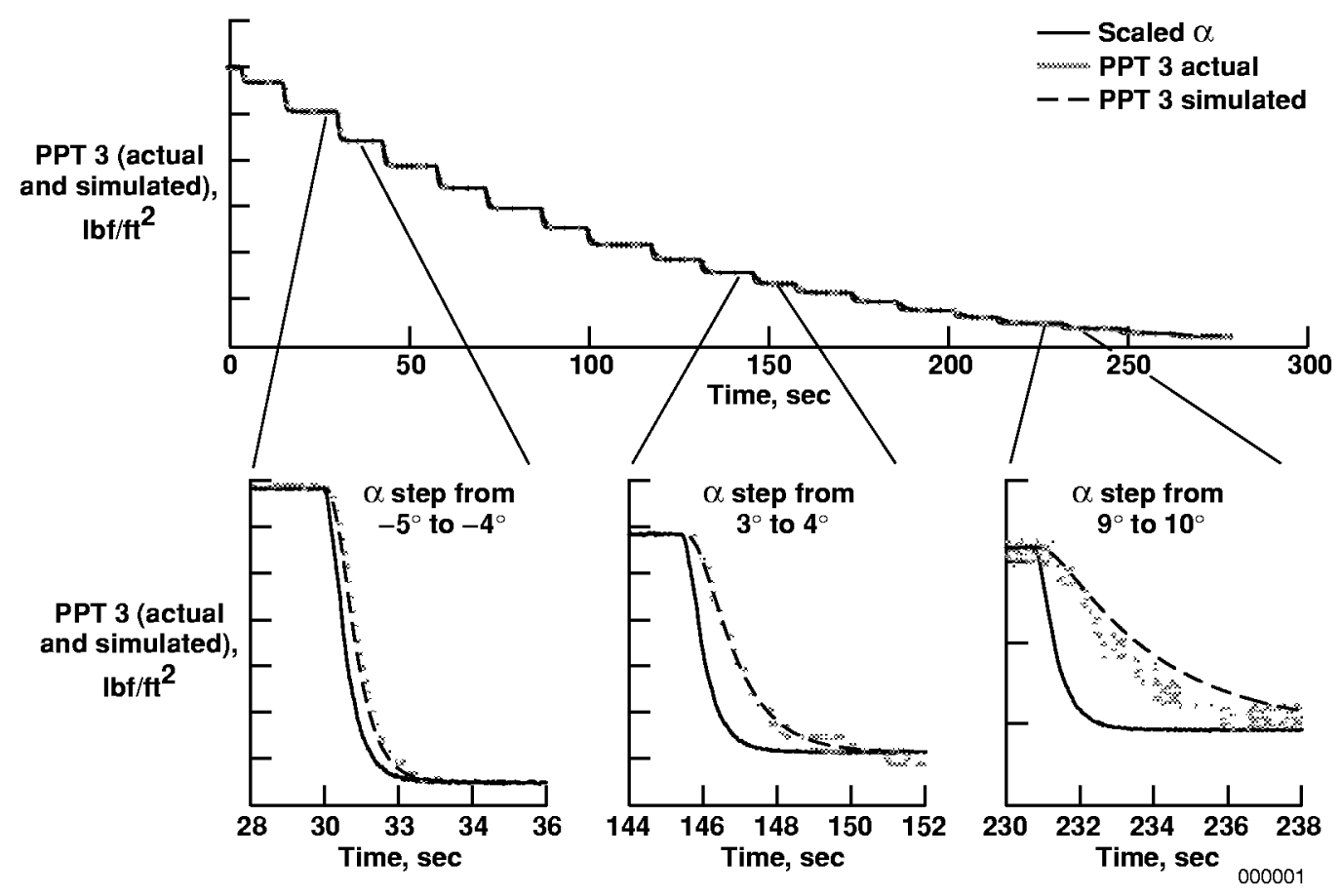

(a) Characteristics for an absolute pressure transducer.

Figure 11. Simulated and actual pressure lag characteristics for a Mach 6 pitch-pause angle-of-attack sweep. 


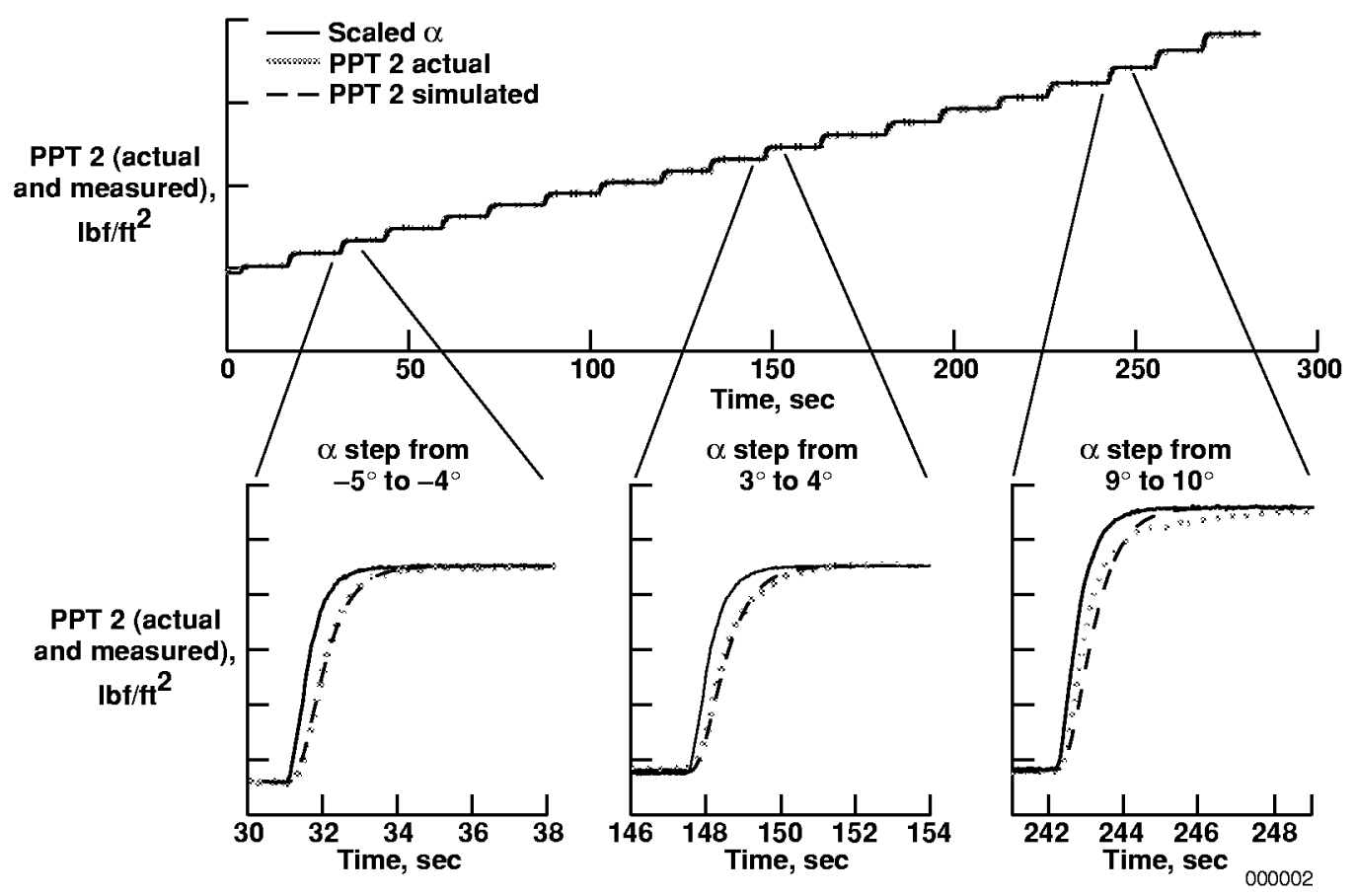

(b) Characteristics for a differential pressure transducer.

Figure 11. Concluded.

Figure 12 is a summary of the lag characterization for all three FADS angle-of-attack signals across the tested Mach number range. These lags are accounted for in the real-time algorithm as previously described in the Real-Time Angle-of-Attack Estimation Algorithm section.

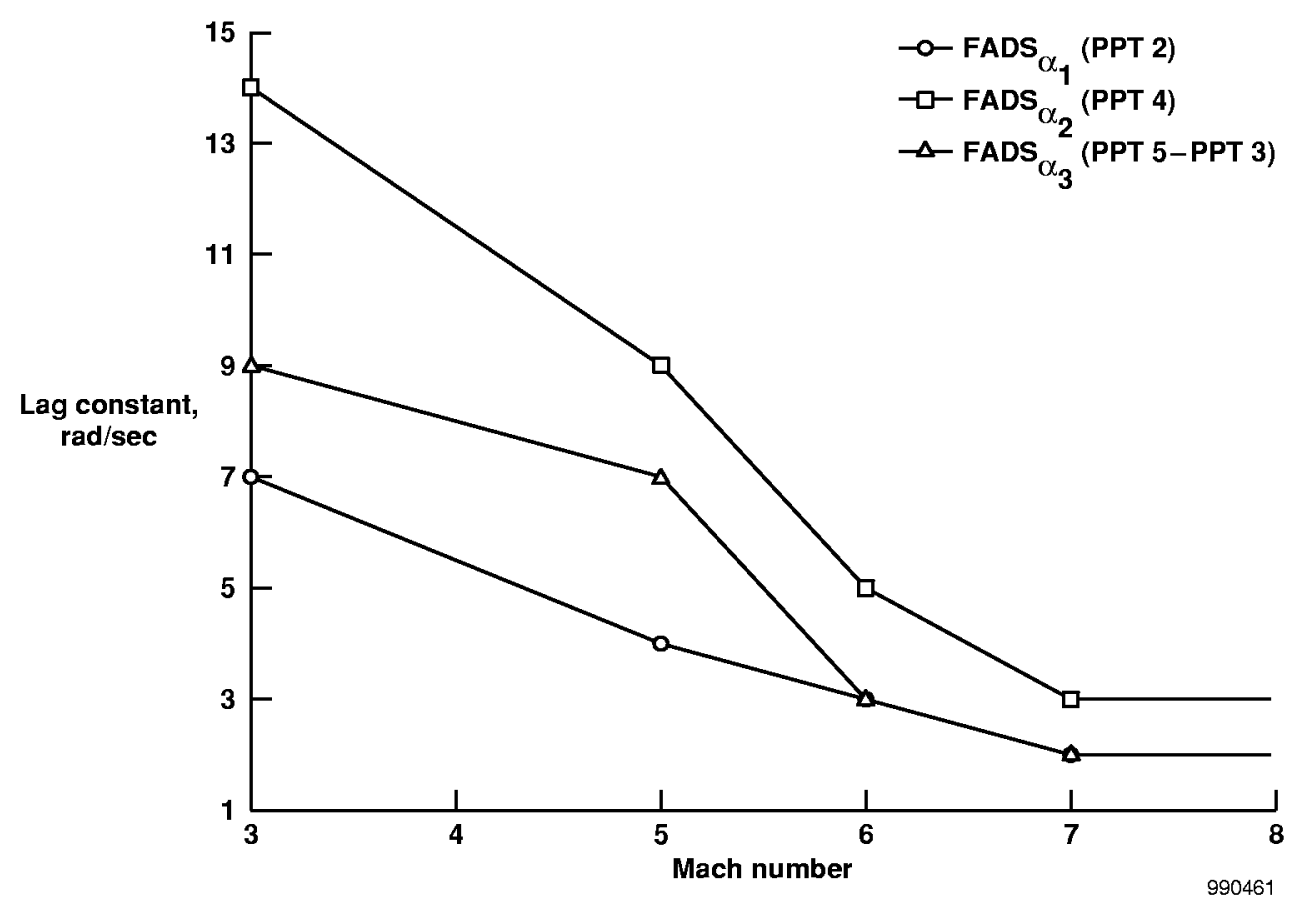

Figure 12. Summary of lag characteristics for all three angle-of-attack estimations as a function of Mach number. 


\section{CONCLUDING REMARKS}

The design of a flush airdata sensing (FADS) system for a sharp-nosed, wedge-shaped vehicle has been described. Real-time angle-of-attack estimation from the FADS system can be used to bias an inertial navigation system angle of attack.

Wind-tunnel tests were conducted to validate the predicted static and dynamic characteristics of the FADS system. The predicted static pressures for a matrix of ports compared well with the wind-tunnel results. Calibration curves were developed to convert differential pressures to angle of attack. Using ports forward of the boundary-layer trip strip results in angle-of-attack errors less than $0.2^{\circ}$ at less than $6^{\circ}$ angle of attack, and less than $0.5^{\circ}$ for the entire angle-of-attack range.

Based on dynamic wind-tunnel results, characterizing the lag from a pair of ports to a differential transducer as a constant first-order lag is possible. The pneumatic lag models are used to determine outof-range or "failed" FADS sensors in the real-time angle-of-attack algorithm.

Wind-tunnel results for static and dynamic pressure data validate the prediction models and the FADS architecture. The wind-tunnel results show that the performance of a FADS system for a sharpnosed, wedge-shaped vehicle can be designed to meet the requirements for accurate measurement of angle of attack for real-time control and for postflight analysis.

Dryden Flight Research Center

National Aeronautics and Space Administration

Edwards, California, December 6, 1999

\section{REFERENCES}

1. Whitmore, Stephen A. and Timothy R. Moes, Measurement Uncertainty and Feasibility Study of a Flush Airdata System for a Hypersonic Flight Experiment, NASA TM-4627, 1994.

2. Enns, Dale F., Dan J. Bugajski, John Carter, and Bob Antoniewicz, "Multi-Application Controls: Robust Nonlinear Mulivariable Aerospace Controls Applications," Fourth High Alpha Conference, CP-10143, vol. 2, 1994.

3. Cary, John P. and Earl R. Keener, Flight Evaluation of the X-15 Ball-Nose Flow-Direction Sensor as an Air-Data System, NASA TN-D-2923, 1965.

4. Siemers, Paul M. III, Martin W. Henry, and James B. Eades, Jr., "Shuttle Entry Air Data System (SEADS) - Advanced Air Data System Results: Air Data Across the Entry Speed Range," Orbiter Experiments (OEX) Aerothermodynamics Symposium, CP-3248, Part 1, Apr. 1995, pp. 49-78.

5. Larson, Terry J., Stephen A. Whitmore, L. J. Ehernberger, J. Blair Johnson, and Paul M. Siemers III, Qualitative Evaluation of a Flush Air Data System at Transonic Speeds and High Angles of Attack, NASA TP-2716, 1987. 
6. Whitmore, Stephen A., Timothy R. Moes, and Terry J. Larson, Preliminary Results From a Subsonic High Angle-of-Attack Flush Air Data Sensing (HI-FADS) System: Design, Calibration, and Flight Test Evaluation, NASA TM-101713, 1990.

7. Whitmore, Stephen A., Brent R. Cobleigh, and Edward A. Haering, Design and Calibration of the X-33 Flush Airdata Sensing (FADS) System, NASA TM-1998-206540, 1998.

8. Anderson, John D., Jr., Hypersonic and High Temperature Gas Dynamics, McGraw-Hill Book Company, New York, 1989.

9. Solid State Electronics Center, Precision Pressure Transducer PPT and PPT-R: User's Manual Version 2.4, Honeywell, Inc., 1996.

10. Ames Research Staff, Equations, Tables, and Charts for Compressible Flow, Report 1135, 1953.

11. Boudreau, A. H., Performance and Operational Characteristics of AEDC/VKF Tunnels A, B, and C, AEDC-TR-80-48, July 1981.

12. Avallone, Eugene A. and Theodore Baumeister III, eds., Marks' Standard Handbook for Mechanical Engineers, 10th ed., McGraw-Hill, Boston, Massachusetts, 1996.

13. Lamb, J. P., Jr., The Influence of Geometry Parameters Upon Lag Error in Airborne Pressure Measuring Systems, WADC TR-57-351, July 1957. 
Public reporting burden for this collection of information is estimated to average 1 hour per response, including the time for reviewing instructions, searching existing data sources, gathering and maintaining the data needed, and completing and reviewing the collection of information. Send comments regarding this burden estimate or any other aspect of this collection of information, including suggestions for reducing this burden, to Washington Headquarters Services, Directorate for Information Operations and Reports, 1215 Jefferson Davis Highway, Suite 1204, Arlington, VA 22202-4302, and to the Office of Management and Budget, Paperwork Reduction Project (0704-0188), Washington, DC 20503

1. AGENCY USE ONLY (Leave blank)

2. REPORT DATE

3. REPORT TYPE AND DATES COVERED

May 2000

Technical Memorandum

4. TITLE AND SUBTITLE

Development of a Flush Airdata Sensing System on a Sharp-Nosed

Vehicle for Flight at Mach 3 to 8

6. AUTHOR(S)

WU 522-51-54-00-50-00-X43

Mark C. Davis, Joseph W. Pahle, John Terry White, Laurie A. Marshall,

Michael J. Mashburn, and Rick Franks

7. PERFORMING ORGANIZATION NAME(S) AND ADDRESS(ES)

NASA Dryden Flight Research Center

P.O. Box 273

Edwards, California 93523-0273

8. PERFORMING ORGANIZATION

REPORT NUMBER

H-2396

9. SPONSORING/MONITORING AGENCY NAME(S) AND ADDRESS(ES)

10. SPONSORING/MONITORING AGENCY REPORT NUMBER

National Aeronautics and Space Administration

Washington, DC 20546-0001

NASA/TM-2000-209017

11. SUPPLEMENTARY NOTES

Author modification of paper presented at 38th AIAA Aerospace Sciences Meeting and Exhibit, 10-13 January 2000,

Reno, NV, AIAA 2000-0504. M. Davis, J. Pahle, J. White and L. Marshall of NASA Dryden Flight Research Center,

Edwards, CA; M. Mashburn of Micro Craft, Inc., Tullahoma, TN; and Rick Franks of Sverdrup Corp., Arnold AFB, TN.

12a. DISTRIBUTION/AVAILABILITY STATEMENT

12b. DISTRIBUTION CODE

Unclassified-Unlimited

Subject Category 06

This report is available at http:/www.dfrc.nasa.gov/DTRS/

13. ABSTRACT (Maximum 200 words)

NASA Dryden Flight Research Center has developed a flush airdata sensing (FADS) system on a sharp-nosed, wedge-shaped vehicle. This paper details the design and calibration of a real-time angle-of-attack estimation scheme developed to meet the onboard airdata measurement requirements for a research vehicle equipped with a supersonic-combustion ramjet engine. The FADS system has been designed to perform in flights at speeds between Mach 3 and Mach 8 and at angles of attack between $-6^{\circ}$ and $12^{\circ}$. The description of the FADS architecture includes port layout, pneumatic design, and hardware integration. Predictive models of static and dynamic performance are compared with wind-tunnel results across the Mach and angle-of-attack range. Results indicate that static angle-of-attack accuracy and pneumatic lag can be adequately characterized and incorporated into a real-time algorithm.

\section{SUBJECT TERMS}

Airdata calibration, FADS, Flush airdata sensing system, Hypersonics, Wedge forebody, Wind tunnel test

17. SECURITY CLASSIFICATION OF REPORT

Unclassified

NSN 7540-01-280-5500
18. SECURITY CLASSIFICATION OF THIS PAGE

Unclassified
19. SECURITY CLASSIFICATION OF ABSTRACT

Unclassified
15. NUMBER OF PAGES

26

16. PRICE CODE

$\mathrm{A} 03$

20. LIMITATION OF ABSTRACT

Unlimited 